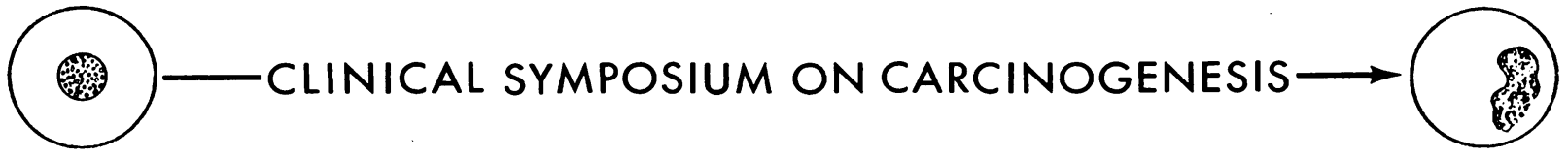

\section{Occupational Factors in Carcinogenesis}

\author{
WILLIAM W. PAYNe, Sc.D.
}

\section{$\mathrm{O}$} CCUPATIONAL CANCER has provided the foundation for environmental carcinogenesis. Here experimental carcinogenesis has found the major yardstick for assessing its relevance to human cancer in terms of compatability of laboratory findings with the circumstances of occupational exposure. The observed latent period in both "spontaneous" and occupational human cancers agrees remarkably with the experimental observation that the appearance of cancer is observed after 50 to 60 percent of the lifespan. In occupational cancers, however, a tendency exists for the tumor to appear at an earlier age than in unexposed groups, and, similarly, an increased dosage of a chemical carcinogen to experimental animals shortens the latent period.

Prophylactic measures in occupational cancers are, as a rule, based on laboratory observations: solubility of the carcinogen, the vehicle, and the exposure time. A highly soluble carcinogen may be removed or eliminated from the body before an effective exposure occurs. The elimination or retention may be influenced by the vehicle. In the laboratory, a carcinogen applied to the ear of a rabbit is less potent than the same dose applied to a crural area, where the sebaceous secretions are most effective as vehicles.

The sites that have been of particular concern in occupational carcinogenesis are the skin, the respiratory system, and the urinary tract (primarily the bladder). Although occupational exposure is usually total body exposure in which the route of entry may be through inhalation, direct contact with or absorption through the skin, or ingestion, all organ systems are not uniformly at risk.

The first reported occupational cancer was a form of cancer of the skin, cancer of the scrotum, among chimney sweeps. The lack of prophylactic measures and the role of the several parameters mentioned by the British surgeon, Sir Percival Pott (1) are impressive.

\section{Polycyclic Aromatic Hydrocarbons}

Cancer of the scrotum, the first identified occupational cancer, also occurs in industrial workers including tar distillery workers, "mule spinners" and other textile workers exposed to lubricating oils, and some petroleum workers.

In the United States a statistical study (2) of a group of workers engaged in manufacturing wax from crude petroleum was initiated in 1947. Cancer-incidence figures for the refinery as a whole were comparable with those for the general male population, but among pressmen engaged in manufacturing wax for 10 years or more, the incidence of scrotal cancer was many times that for the general male population. This study most effectively shows the need, in investigating cancer hazards in industry, to examine small groups with specific exposures.

Dr. Payne is deputy scientific director for etiology, National Cancer Institute, Public Health Service, Bethesda, Md. 
The high incidence in this small group of workers would not have been observed if all the personnel of the plant had been considered.

Clinically associating the occurrence of cancer of the skin with exposure to tar, petroleum, and combustion products led to laboratory experiments. The first notable experiment in carcinogenesis was the confirmation of the carcinogenicity of coal tar by Yamagiwa and Ichikawa in 1915 (3). They produced carcinomas by painting this material on the inner surface of the ears of domestic rabbits. In 1925 Kennaway (4) showed that the pyrolysis of a number of organic substances produced carcinogenic tars and that carcinogenic materials could be produced synthetically from pure compounds. In 1929 the first pure carcinogenic chemical, 1,2,5,6-dibenzanthracene, was discovered by Kennaway (5).

In 1932 Cook and associates (6) published the results of testing a number of polycyclic aromatic hydrocarbons consisting entirely of benzene rings. In 1933 Cook and co-workers (y) isolated and identified benzpyrene as one of the carcinogenic chemicals present in coal tar. During these years it was hoped that a single class of compounds would be found to be responsible for the causation of all cancers, but we can appreciate now the futility of this hope.

The list of polycyclic and other compounds that have been studied is extensive (8) and with the development of new products by the chemical industry the list of compounds that have not been tested in animals is lengthening. The need for better testing or screening procedures is becoming more urgent as the list grows.

Benzo $[a]$ pyrene, or 3,4-benzpyrene, has been of particular interest as a carcinogen because it has been found in many crude carcinogenic materials (for example, coal tar) and has been identified in city air, cigarette smoke, and generally wherever the combustion of organic matter is incomplete.

Although there is no direct proof that any of the polycyclic aromatic hydrocarbons are carcinogenic for man, little doubt should remain that they have a causal role, either directly or combined with other factors, in human cancer. Evidence that exposures in industry to crude organic products result in an increased risk to cancer of the skin and possibly the lung is extensive (9).

\section{Aromatic Amines}

Although most early associations between occupation and the occurrence of cancer were in industries where persons were exposed to polycyclic aromatic hydrocarbons, another group of organic compounds was among the chemicals that were suspected of being cancer hazards, the aromatic amines. As early as 1895 an association was observed in the dye industry between the production of aromatic amines, particularly aniline, and the occurrence of bladder cancer.

Because it was suggested that the cancers among workers manufacturing the dye magenta were due to aniline, the disease has been referred to as aniline cancer. It was found in the United States and confirmed in England that the agent was not aniline but benzidine, or 2-naphthylamine.

Experimental bladder cancer stems from the work of Hueper and co-workers (10), who in 1938 produced bladder cancer in dogs by treating them with 2-naphthylamine by subcutaneous injection and feeding. Wiley then showed that dogs metabolized the compound to the sulfuric ester of 2-amino-1-naphthol, thus demonstrating the important fact that a metabolite was the carcinogenic agent rather than the original compound. In industry it has been found that the hazard of using 2-naphthylamine or beta-naphthylamine is extremely difficult to control because the route of entry may be inhalation, skin absorption, or ingestion, producing bladder tumors in virtually 100 percent of persons exposed. In many instances use of the compound has been discontinued. One State has prohibited its manufacture.

\section{Other Organic Compounds}

Another group of organic chemicals, the epoxides, lactones, and peroxy compounds, has more recently become of interest as carcinogenic agents. Kotin and Falk (11) in 1955 suggested that epoxides and peroxy compounds formed by the oxidation of olefins may be carcinogenic air pollutants. Skin tumors were produced in mice 
with atmospheric extracts free of aromatic hydrocarbons. An effective bactericidal agent, beta-propiolactone, has been shown by Van Duuren and co-workers (12) to be carcinogenic for experimental animals. It was proposed as a general hospital bactericidal agent until its carcinogenic potential was realized. Aliphatic organic compounds are becoming of increasing importance as carcinogens or promoting agents.

\section{Inorganic Compounds as Carcinogens for Man}

As early as 1890 chromium was suspected as an industrial carcinogen when Neuman (13) reported the occurrence of a case of cancer of the nose in a chromium pigment worker in Scotland. This and later reports of individual cases of cancer in workers exposed to chromium in the processing of ore or in the production of chromium pigments in Germany provided additional evidence. Studies of personnel records of persons employed in chromate-producing plants in the United States and Great Britain show conclusively that workers engaged in the production of chromium compounds from chromite ore have an abnormally high risk of developing bronchogenic carcinoma.

Experimental studies by Hueper and Payne $(14,15)$ have shown that pure chromium compounds will produce malignant tumors, both sarcomas and carcinomas, in a variety of tissues in rats and mice. Even though bronchogenic carcinomas have not been produced by inhalation in experimental animals, little doubt remains that chromium is the agent responsible for the high incidence of cancer of the lung in chese workers. The moderately soluble hexavalent chromium compounds were most potent in animals, apparently because they were retained long enough to provide an effective dose; whereas, when the extremely insoluble compounds were administered, the chromium was released too slowly to be effective. The action of carcinogens is, for the most part, analogous to all pharmacological actions. The response is proportional to the dose, which in turn is a product of concentration and time.

The first cases of cancer of the lung and nasal passages among workers in a nickel refinery in South Wales were reported in 1939. Doll (16) has concluded that for these workers, during the period 1948 to 1956 , the risk of dying of lung cancer was nearly 5 times the nonindustrial risk, and that for nasal cancer, 150 times the "normal" risk.

The implantation of powdered metallic nickel in rats by Hueper (17) resulted in the production of sarcomas in about 28 percent of the animals. More recently, Gilman and Ruckerbauer (18) in a study of dust from a Canadian nickel refinery produced sarcomas in two strains of rats and in mice by intramuscular injection of the crude dust. Gilman (19) tested fractions of the dust and concluded that nickel sulfide was the material responsible for the carcinogenic activity of the dust. In a study by Payne (20) of a wide range of nickel compounds, the relation between solubility and carcinogenic potency was found to be similar to that for chromium.

One of the most controversial of known or suspected environmental carcinogens is arsenic. As early as 1820 arsenical compounds were suspected of carcinogenic action. Although few if any incidence rates are available, there is little disagreement that the medicinal use of arsenic compounds has resulted in the production of skin cancers in man where there is evidence of chronic arsenic poisoning, but the causal relation to cancer of other sites appears equivocal. Sites in addition to the skin have been suspected, including the urinary tract, stomach, esophagus, oral cavity, and respiratory tract.

Other occupational exposures than those resulting from the manufacture and use of arsenical pesticides occur in the smelting of ores that contain appreciable quantities of arsenic and many metals. The evaluation of data from such exposures is difficult because many of these ores contain recognized or suspected carcinogenic compounds. Animal experiments designed to test the carcinogenicity of arsenical compounds have been either negative or inconclusive.

The first case in which asbestosis was associated with cancer of the lung was described by Lynch and Smith (21) in 1935 in the United States. Between that time and 1958, 80 to 100 cases were reported from England, Canada, Germany, and the United States. Doll (22) studied 113 men who had worked for 20 years 
or longer where they were liable to be exposed to asbestos dust and found that 39 deaths had occurred compared with 15.4 deaths expected from the age-specific national morbidity rates. Of the 39 deaths, 11 were due to lung cancer, whereas less than 1 would have been expected. All 11 lung cancer deaths were associated with asbestosis.

Additional evidence of the carcinogenicity of asbestos is given in a recent report (23) of 47 cases of mesothelioma, a tumor that is generally uncommon, among residents of northwestern Cape Province of the Union of South Africa. In 45 of the cases, a possible association with exposure to one form of asbestos was established.

Asbestosis can be produced in experimental animals by exposure to asbestos dust, but efforts to produce cancer of the lung in this way have been unsuccessful.

One characteristic of occupational cancers, regardless of the agent, is the long latent period from the first exposure to the appearance of the cancer. The average observed latent period for some of the agents that have been discussed are tar, 20-24 years; asbestos, 18 years ; chromates, 15 years; and aromatic amines, 11-15 years. Another interesting observation is that the cancer may develop even though the person has changed occupations and is no longer exposed to the agent. This, too, may occur several years later.

\section{Importance of Studying Occupational Exposures}

Opportunities to observe the effects of carcinogenic agents in man are rare, but occupational data including employment histories, environmental exposure in the plant, and knowledge of the chemical and physical properties of the raw materials, as well as intermediate and finished products, enable us to partially bridge the gap between the experimental animal and man.

From the study of occupational groups, a useful methodology has evolved for studying the causes of cancer in man. For example, let us review the history of chromium as a carcinogen. There have been clinical cases-scattered cases with no denominator for the statistician but keen observation on the part of the clinician. Retrospective studies which followed clearly established that workers in plants producing chromium chemicals from the chromate ore had an unusual liability to cancer of the lung, but the specific agent was not identified. Finally, tumors were produced in the laboratory by the administration of pure chromium compounds and several intermediate products containing these compounds.

Some of the more skeptical critics maintain that proof is incomplete until the type of cancer occurring in man has been produced by inhalation. We anticipate that this final step will be accomplished through current studies of combined factors in pulmonary carcinogenesis and through epidemiologic studies of workers exposed to chromium compounds, such as painters engaged in spraying zinc chromate paint.

Some studies of specific occupational groups may be used to obtain a more definitive answer concerning the carcinogenicity of a suspected agent than can be obtained from studies of larger population groups. A review of vital statistics for former military personnel in Great Britain and the United States who were exposed to mustard gas during World War I provided suggestive information that exposure to this agent produced cancer of the lung. However, it is expected that a well-planned epidemiologic study of a group of workers in Japan who were exposed while manufacturing this gas will provide a conclusive answer.

To date our more effective efforts in the prevention of cancer have been in industry by substituting a safer chemical for a carcinogenic one; for example, eliminating the use of betanaphthylamine to prevent cancer of the bladder, improved manufacturing processes, the containment of hazardous chemicals, and more effective industrial hygiene and medical programs.

Instances have occurred in which the exposure of occupational groups to a carcinogenic agent has been avoided by animal studies. In 1940 a patent was issued for an insecticide containing various derivatives of fluorene, which is derived from coal tar. Many of these derivatives including 2-acetaminofluorene were found, after feeding them to experimental animals, to produce tumors in a number of organs, notably the bladder, liver, and lungs. As a result, the chemical is not being used as an insecticide. Similarly, nitrosoamine has not been 
marketed as a solvent because of its carcinogenicity.

Although the number of people in the occupational groups I have mentioned may not be large, undoubtedly some persons have lived longer, happier, cancer-free lives as a result of the elimination of known carcinogens from their environment.

\section{REFERENCES}

(1) Pott, P.: Chirurgical observations relative to the cataract, the polypus of the nose, the cancer of the scrotum, the different kinds of ruptures, and the mortification of the toes and feet. Hawes, Clarke and Collins, London, 1775.

(2) Hendricks, N. V., Berry, C. M., Lione, J. G., and Thorpe, J. J.: Cancer of the scrotum in wax pressmen. I. Epidemiology. AMA Arch Industr Health 19 : 524 (1959).

(3) Yamagiwa, K., and Ichikawa, K. : Experimental study of the pathogenesis of carcinoma. J Cancer Res 1: 1 (1918).

(4) Kennaway, E. L.: Experiments on cancer-producing substance. Brit Med J 2: 1 (1925).

(5) Kennaway, E. L., and Hieger, I.: Carcinogenic substances and their fluorescence spectra. Brit Med J 1: 1044 (1930).

(6) Cook, J. W., Hieger, I., Kennaway, E. L., and Mayneord, W. V.: The production of cancer by pure hydrocarbons. Pt. 1, Series B. Proc Royal Soc 111 : 455 (1932).

(7) Cook, J. W., Hewett, C. L., and Hieger, I. : The isolation of a cancer-producing hydrocarbon from coal tar. J Chem Soc 1: 395 (1933).

(8) Shubik, P., and Hartwell, J. L.: Survey of compounds that have been tested for carcinogenic activity. PHS Publication No. 149, supp. 1. U.S. Government Printing Office, Washington, D.C., 1957.

(9) Falk, H. L., Kotin, P., and Mehler, A. : Polycyclic hydrocarbons as carcinogens for man. Arch Environ Health 8: 721 (1964).

(10) Hueper, W. C., Wiley, F., and Wolfe, H. D.: Experimental production of bladder tumors in dogs by administration of betanaphthylamine. J Industr Hyg Toxicol 20: 49 (1938).
(11) Kotin, P., and Falk, H.: Production of tumors in C57 black mice with atmospheric-extracted aliphatic hydrocarbons. Proc Amer Assoc Cancer Res 2: 30 (1955).

(12) Van Duuren, B. L., et al.: Carcinogenicity of epoxides, lactones and peroxy compounds. J Nat Cancer Inst 31: 41 (1963).

(13) Neuman, D.: A case of adeno-carcinoma of the left inferior turbinated body and perforation of the nasal septum in the person of a worker in chrome pigment. Glasgow Med J 33: 469 (1890).

(14) Hueper, W. C., and Payne, W. W. : Experimental cancers in rats produced by chromium compounds and their significance to industry and public health. Amer Industr Hyg Assoc J 20: 274 (1959).

(15) Payne, W. W.: Production of cancers in mice and rats by chromium compounds. AMA Arch Industr Health 21 : 530 (1960).

(16) Doll, R.: Occupational lung cancer; a review. Brit J Industr Med 16: 181 (1959).

(17) Hueper, W. C.: Experimental studies in metal cancerogenesis. IV. Cancer produced by parenterally introduced metallic nickel. J Nat Cancer Inst 16: 55 (1955).

(18) Gilman, J. P. W., and Ruckerbauer, G. M. : Metal carcinogenesis. I. Observations on the carcinogenicity of a refinery dust, cobalt oxide, and colloidal thorium dioxide. Cancer Res 22: 152 (1962).

(19) Gilman, J. P. W.: Metal carcinogenesis. II. A study of the carcinogenic activity of cobalt, copper, iron, and nickel compounds. Cancer Res 22 : 158 (1962).

(20) Payne, W. W.: Carcinogenicity of nickel compounds in experimental animals. Proc Amer Assoc Cancer Res 5: 50 (1964).

(21) Lynch, K. M., and Smith, W. A. : Pulmonary asbestosis : Carcinoma of lung in asbesto-silicosis. Amer J Cancer 24: 56 (1935).

(22) Doll, R.: Mortality from lung cancer in asbestos workers. Brit J Industr Med 12 : 81 (1955).

(23) Wagner, J. C., Sleggs, C. A., and Marchand, P.: Diffuse pleural mesothelioma and asbestos exposure in the northwestern Cape Province. Brit J Industr Med $17: 260$ (1960). 